\title{
Assessment criteria for optimization of parameters affecting to local wagon-flows at railway sites
}

\author{
Sherzod Jumayev ${ }^{* 0000-0003-4905-9620]}$, Sakijan Khudayberganov, Oybek Achilov, and Munira \\ Allamuratova \\ Tashkent State Transport University, Tashkent, Uzbekistan
}

\begin{abstract}
Various methods can be used to obtain the most reliable results in optimizing the parameters that directly affect the acceleration of the local wagon-flows at railway sites. First of all, to use these methods, it is necessary to create a multidimensional criterion for evaluating the parameters. Assessment criteria include overtime of trains at intermediate stations, excessive costs associated with the delivery of wagons, irrationality of the geographical location of freight facilities at intermediate stations, variability of hauling and carrying capacity of hauls, processing of trains at technical stations and their time of departure. Trains can take the level of execution of the movement schedule and so on. To optimally solve multidimensional assessment criteria, it is first necessary to find the best target function, which considers the opposite characteristics of all assessment criteria, "contributes" to the final result of each assessment criteria and simultaneously expressed in different units. It should be able to compare. This paper provides a systematic solution to the above issues based on the assessment criteria.
\end{abstract}

\section{Introduction}

Currently, modern measures are being developed to optimize the wagon- flow on the world's railways, including Canada, Japan, South Korea, China, Russia, Kazakhstan and many other countries with integrated railway networks [1-7]. In particular, JSC "Uzbekistan Railways" is working on this issue. Optimizing the wagon-flows between two or more technical stations allows increasing the efficiency of local work performed at the stations.

In connection with the loss in the presence of a market of the relevance of one of the main criteria of the system for organizing wagon-flows - reducing the time of wagon turnover, it is necessary to change the assessment of options for the plan of forming trains at the cost of the given wagon-hours. Therefore, as a replacement, he was asked to meet the delivery deadlines. At the same time, in the conditions of the privatized car fleet, a combination of criteria was required to comply with the delivery time of goods and minimize the processing of wagon-flows at technical stations [8]. Optimization of wagon-

* Corresponding author: shbjumayev_92@mail.ru 
flow in the railway system can be done by influencing their following two indicators: acceleration of wagon-flow and selection of wagon-flow directions using rational methods.

Determining the direction of movement of local wagon-flows includes the following:

- formation of the zone of stations where shunting locomotives provide freight operations services at base stations;

- technical and economic evaluation of the options for sorting and attachment of these zones to the station stations following the criteria of minimum operating costs in the case of limited loading of service equipment at the railway junction with limited loads and the allowable time of wagons at the junction;

- amendments to the attachment of the specified zones following the conditions of interaction with the train construction plan ("walking" at the nodes to increase transit wagon-flows);

- development of attachment options for work at night, on holidays and weekends [9].

Taking into account the directions of movement of the local wagons identified above, the following can be cited as factors influencing their deceleration:

- the number of intermediate stations located between technical stations $(K)$;

- the wagon-flows moving in the odd direction relative to the location of intermediate stations $(X)$ and the wagon-flows moving in their double direction $(Y)$;

- the number of processes performed at intermediate stations $(\Theta)$;

- time of local trains at intermediate stations $\left(T_{i n}\right)$;

- number of intermediate station tracks $\left(D_{s t}\right)$ and their share of occupancy $\left(\phi_{y}\right)$;

- distance between the station and intermediate stations $\left(L_{i s}, L_{s d}\right)$;

- the number of units of shunting operations at intermediate stations $\left(W_{x}\right)$ and their types $\left(T_{l}\right.$ or $\left.S h_{l}\right)$;

- norms established for trains on the railway site: on conditional length of trains $\left(L_{w}\right)$ and by their weight $\left(G_{w}\right)$;

- installed speed for railway site $\left(v_{s p}\right)$;

- the degree to which the railway site is occupied by other trains: by passenger trains $\left(£_{\text {pass }}\right)$ and by other freight trains other than trains carrying local work $\left(£_{\text {car }}\right)$;

- type of weighing of the plot $(E$ or $S h)$;

- equipment of the railway site ( $A b$ or $H A b)$;

- slope of roads at railway site $\left(i_{s}\right)$;

- random factors: natural $\left(J_{r n}\right)$ and man-made $\left(J_{r m}\right)$.

Researched at Fig. 1. the main factors influencing the slowdown the local wagon-flows in the following four types. There are:

- technical factors;

- technological factors;

- factors related to the management process;

- natural factors.

Their location and the movement of wagons in them play an important role in developing measures to accelerate the local wagon-flows. One of the best ways to find the optimal solution and choose the main assessment criteria based on mathematical approaches is to take measures to accelerate the local wagon-flows. As well as, suggestions for solving the problem of wagon-flow in many scientific works. Including, Wang et al. [10] proposed a stochastic dependent chance multi-objective programming model, which aims to maximize the reliability of the car flow routing plan and minimize the expected total cost. Nong et al. [11] introduced a distributed computing method to solve the problem that the computational complexity of car flow routing optimization increases exponentially with the number of nodes and the size of the car flow in the rail network. 


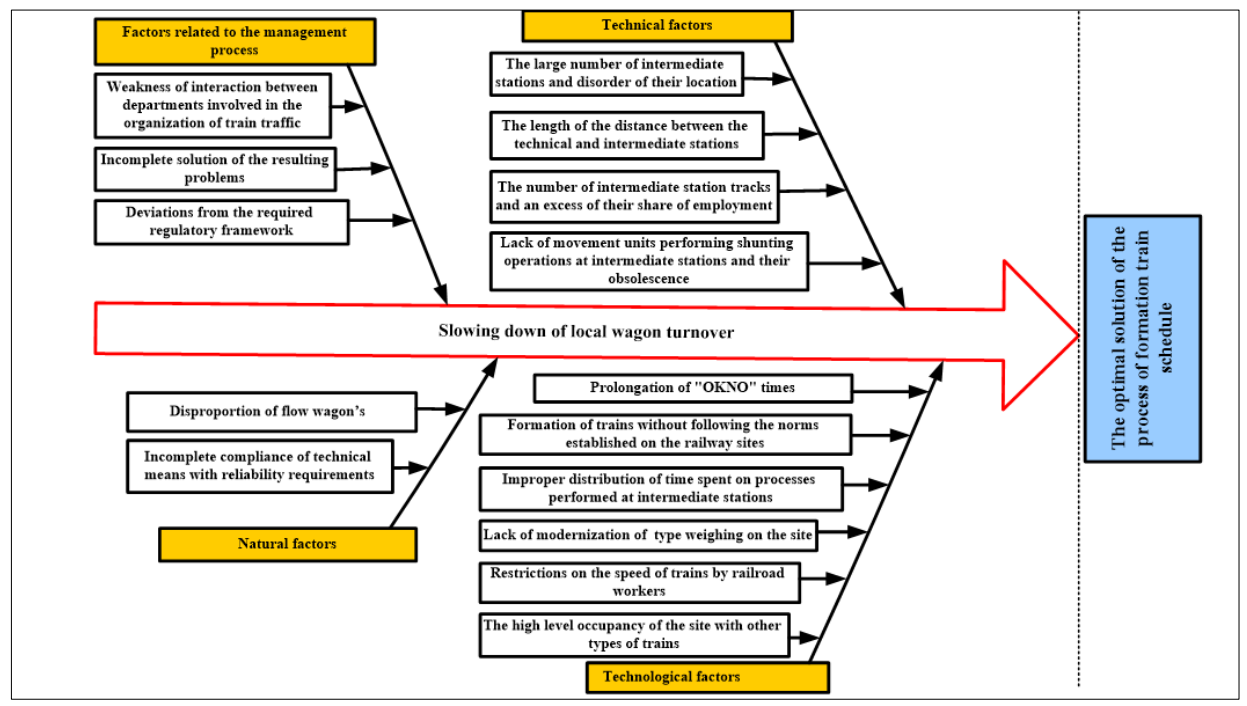

Fig. 1. Research of factors affecting local wagon turnover

\section{Materials and Methods}

Mathematical approach to speeding up of local wagon-flows. The number of possible delivery schemes of local wagons to their destinations will depend on the number of intermediate stations located in it, the number of wagons delivered and other parameters. We use the following scheme (Fig. 2.) To conduct mathematical research on accelerating the local wagon-flows.

According to Fig. 2., it was introduced to denote the number of wagons that could move in the single direction by $X$, and the wagon-flows moving in the double direction by $Y$. The flow sets of wagons moving in single and double directions are given in (1), (2).

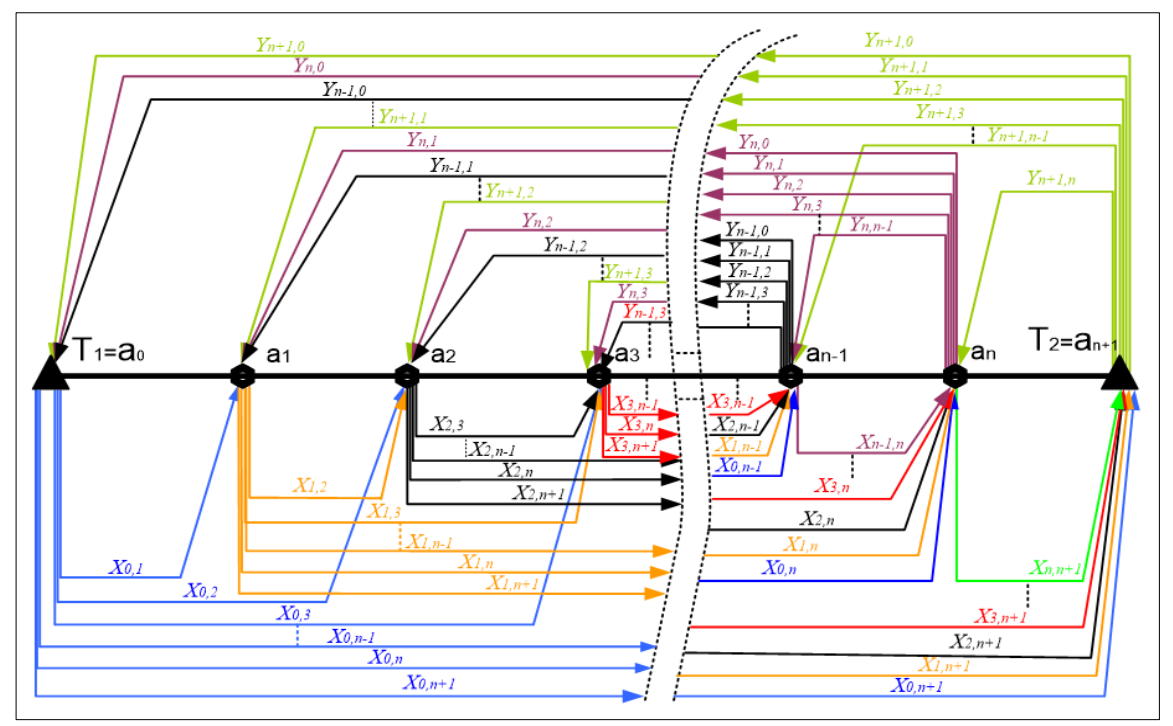

Fig. 2. Algebraic probability graph of wagons delivery to their destinations (on the example of local wagon turnover) 
A set of wagon-flows moving in a single direction $(X)$ :

$$
X=\left\{\begin{array}{c}
x_{0,1}, x_{0,2}, x_{0,3}, \ldots, x_{0, n-1}, x_{0, n}, x_{0, n+1} \\
x_{1,2}, x_{1,3}, \ldots, x_{1, n-1}, x_{1, n}, x_{1, n+1} \\
x_{2,3}, \ldots, x_{2, n-1}, x_{2, n}, x_{2, n+1} \\
\ldots \ldots \ldots \ldots \\
\ldots \ldots \ldots \ldots \\
x_{n-1, n}, x_{n-1, n+1} \\
x_{n, n+1}
\end{array}\right\}
$$

A set of wagon-flows moving in the direction of the pair $(\boldsymbol{Y})$ :

$$
Y=\left\{\begin{array}{c}
y_{1,0}, y_{2,0}, y_{3,0}, \ldots ., y_{n-1,0}, y_{n, 0}, y_{n+1,0} \\
y_{2,1}, y_{3,1}, \ldots, y_{n-1,1}, y_{n, 1}, y_{n+1,1} \\
y_{3,2}, \ldots, y_{n-1,2}, y_{n, 2}, y_{n+1,2} \\
\ldots \ldots \ldots \ldots \\
\ldots \ldots \ldots \ldots \\
y_{n, n-1}, y_{n+1, n-1} \\
y_{n+1, n}
\end{array}\right\}
$$

The coefficients (3-6) are given in the ratio of the wagon-flows entering the station to the wagon-flows leaving them. The denominator in the image of the fraction represents the wagon-flows entering the station, and the denominator represents the wagon-flows leaving this station.

For the first station:

$$
\forall_{1}=\frac{\left(x_{0,1}\right)+y_{2,1}+y_{3,1}+y_{4,1}+\cdots+y_{n-1,1}+y_{n, 1}+y_{n+1,1}}{\left(y_{1,0}\right)+x_{1,2}+x_{1,3}+x_{1,4}+\cdots \cdot+x_{1, n-1}+x_{1, n}+x_{1, n+1}}
$$

For the second station:

$$
\forall_{2}=\frac{\left(x_{0,2}+x_{1,2}\right)+y_{3,2}+y_{4,2}+\cdots+y_{n-1,2}+y_{n, 2}+y_{n+1,2}}{\left(y_{2,1}+y_{2,0}\right)+x_{2,3}+x_{2,4}+\cdots+x_{2, n-1}+x_{2, n}+x_{2, n+1}}
$$

For the third station:

$$
\forall_{3}=\frac{\left(x_{0,3}+x_{1,3}+x_{2,3}\right)+y_{4,3}+\cdots+y_{n-1,3}+y_{n, 3}+y_{n+1,3}}{\left(y_{3,0}+y_{3,1}+y_{3,2}\right)+x_{3,4}+\cdots+x_{3, n-1}+x_{3, n}+x_{3, n+1}}
$$

For the n-th station:

$$
\forall_{n}=\frac{\left(x_{0, n}+x_{1, n}+x_{2, n}+x_{3, n}+\cdots+x_{n-2, n}+x_{n-1, n}\right)+y_{n+1, n}}{\left(y_{n, 0}+y_{n, 1}+y_{n, 2}+y_{n, 3}+\cdots+y_{n, n-2}+y_{n, n-1}\right)+x_{n, n+1}}
$$

The closer the value of this coefficient is to " 1 " for each station, the higher the wagonflow efficiency and wagon turnover will be in this railway site:

$$
\lim _{X, Y \rightarrow \infty} \forall_{n}=1
$$

Hence, if the set of factors $(A)$ affecting the acceleration of the local wagon-flows is given by the following relation, it will be possible to achieve the highest efficiency in this site: 


$$
\mathrm{A}=\left\{\begin{array}{c}
f\left(K, \Theta, T_{i n}, \phi_{y}, L_{i s}, L_{s d}, €_{\text {pass }}, €_{c a r}, i_{s}, J_{r n}, J_{r m} \ldots\right) \rightarrow \min \\
f\left(\mathrm{X}, Y, D_{s t}, W_{x}, L_{w}, G_{w}, v_{s p}, \ldots\right) \rightarrow \max
\end{array}\right\}
$$

where $\mathrm{A}$ is a set of accepted values of optimized parameters, consisting of several elements.

We are looking for a solution to optimize the parameters in the (8) expression. We enter a definition for the given parameters, i.e. $\mathrm{a}_{1}=K, \mathrm{a}_{2}=\Theta, \mathrm{a}_{3}=T_{i n}, \ldots, \mathrm{a}_{\mathrm{nn}}=v_{s p}$ and other.

Assessment criteria for optimization of parameters affecting the acceleration of local wagon traffic. To optimize the movement of local wagons, it is necessary to regulate and simplify the parameters that affect the acceleration of the local wagon-flows. There are different options for sorting the factors that affect the acceleration of the local wagon-flows. Suppose that there are different input and output flows of trains in the study area that correspond to certain volumes of work and have these characteristics (Fig. 2). On this railway site, each wagon stream can be serviced using a portion of the equipment and facilities available at the stations (e.g., shunting locomotives, station tracks, maintenance crews, etc.).

It is also planned to develop a set of assessment criteria that will reflect the optimisation objectives in the study of the site and allow the evaluation of certain structural features. To do this, the parameters that need to be optimized above are also defined. As a result of servicing each flow, a set of regulated output characteristics (values of optimization criteria) corresponding to the maintenance of this flow in a particular circuit is adopted (Fig. 3).

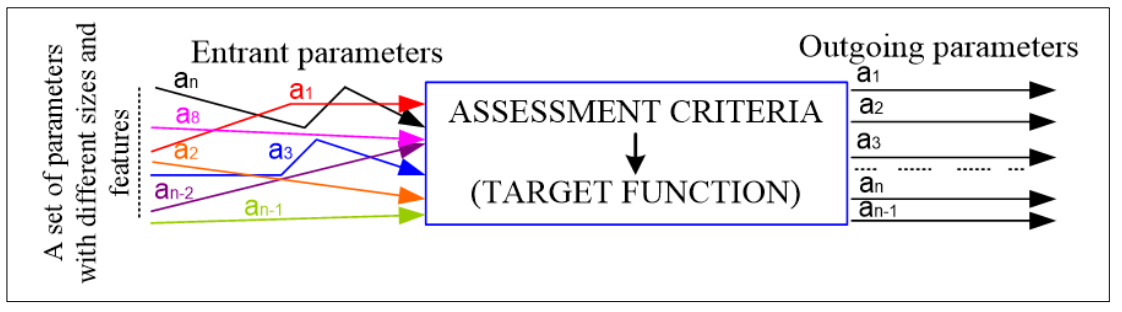

Fig. 3. Sample scheme of the selected assessment criteria

Based on Figure 3, the characteristics of such vectors (entrant parameters) can be characterized by non-negative numbers with a priority level. Such numbers can be sorted by their level of importance or given weights that consider these levels of importance. For each component of the value vector of this assessment criteria, the direction of its improvement should be indicated (i.e., the higher (lower) the value of this assessment criteria. The more consistent this scheme should be with this assessment criteria flow). To do this, the task is to select the target function that corresponds to the vectors of the values of the assessment criteria in determining the optimal scheme for the wagon-flows or working volume.

So far, various solutions to almost all optimization problems have been identified in science, and the method of solving them can be demonstrated by the exact mathematical optimization problems known to us. These include extreme problems for multivariable functions, problems for inductive functions, variational problems, and more. Suppose the mean of the values entered in them is used without accepting or using additional assumptions of a different nature. In that case, the method chosen above can also solve problems involving any random values or random functions, i.e. the exact mathematical optimization problem set for the best parameter search is solved. However, the number of such issues is small and includes various uncertainties. The challenge is to formulate 
additional assumptions using informal analysis that minimize existing uncertainties with rigorously developed optimization problems.

Objective function and possibility methods for selection of assessment criteria. Let's look at two possible ways to select the assessment criteria:

- ideal point method;

- a simplified method of calculations based on an economic and mathematical model.

Each assessment criteria may have relatively better or worse values, depending on the initial conditions. We accept the best value of the assessment criteria as a conditionally acceptable option.

It is known that, among all the assessment criteria, it is difficult to find a scheme of such values of the optimized parameters, which can be the best at the same time or accept the optimal values. For example, a sharp increase in the wagon-flows will lead to a decrease in their carrying capacity, taking into account the current capacity of stations and railway sites, but at the same time increase the "delivery time" of wagons; the workload of employees involved in train traffic will increase; expectations in the performance of technological operations will increase. Also, if the current wagon-flow accelerates, the delivery time will be shortened, the cost of using the railway infrastructure will be reduced, the staff's work efficiency will be increased, and so on. Thus, in determining the set of values of the various parameters in this way, it is chosen that their values are as close as possible to those that are rational.

According to [12], the enlarged view of the algorithm consists of three stages:

- the first stage (step) of the algorithm involves the calculation of the values of the assessment criteria and their weight values;

- in the second stage, the values of the target function and the weights of the assessment criteria at different values are calculated;

- in the third stage, the obtained values of the target function are placed in an ordered sequence.

If the accepted assessment criteria comparison function is described or another selection algorithm is installed, this problem becomes an optimization problem.

Let there be two rows $n$ size $a_{1 j}, a_{2 j}, a_{3 j}, \ldots$ and $a_{l k}, a_{2 k}, a_{3 k}, \ldots$ of numbers (selected according to the data given in expression (8)).

Each component of the series corresponds to the numbers $\lambda_{i}, i=1,2,3, \ldots, n$ which are independent of changes in this component and indicate its weight among the values of the assessment criteria.

For all values of $i=1,2,3, \ldots, n$ in $\lambda_{i} \geq 0$, under the standardization condition, the limits on, $\lambda_{i}$ are determined.

$$
\sum_{i=1}^{n} \lambda_{i}=1
$$

Different approaches can be used to address this issue. The first method is the ideal point method, in which the minimum value of the sum of their squares of deviations is taken from the individual optimal values for each scheme of the assessment criteria and the workload:

$$
F_{1}=\min \sum_{i}\left(\frac{\alpha_{i j}(\mathrm{~A})-\alpha_{i o p t}}{\alpha_{i o p t}}\right)^{2} \cdot \lambda_{i}
$$

where is a set of accepted values of optimized parameters consisting of one element;

A

$i$ is the sequence number of the optimization criteria $i=1,2, \ldots, n$;

$\lambda_{i} \quad$ is the weight of the orderly $i$-th assessment criteria; 
$\alpha_{i j}$ (A) is the value of the $\mathrm{i}$-optimization criterion in the parameter values in the $j$-th set;

$\alpha_{i o p t}$ is the optimal value of the $i-t h$ assessment criteria for a given initial condition.

As an alternative way to solve the problem, it is possible to consider a simplified calculation method based on an economic and mathematical model. It is accepted to use the target assessment function:

$$
F_{2}=\sum_{i}\left(\frac{\left(\alpha_{i j}-\alpha_{i k}\right)}{\left(\alpha_{i j}+\alpha_{i k}\right) / 2}\right) \cdot \lambda_{i}( \pm 1) \rightarrow \max
$$

where $\alpha_{i j} \quad$ is the value of the $i$ - $t$ th optimization criteria corresponding to the option $j$-th;

$\alpha_{i k} \quad$ is the value of the $i$-th optimization criteria corresponding to the option $k$-th;

$\lambda_{i}$ is the weight of the orderly $i-t h$ assessment criteria.

An improved vector of the target function is determined to sort the obtained values and place them in descending order of priority of the factors influencing the wagon-flows. As mentioned above, the values of, $\lambda_{i}=1,2,3, \ldots, n$ depend on the level of significance of the $i$-th component (assessment criteria) and their selection is made based on practical calculations depending on this level.

Particular attention should be paid to the problem of estimating the complexity of the algorithm for placing a given series of numbers in a range. The assigned task is directly related to the tasks in the sequence.

The paper [13] presents a large part of the problem-solving algorithms similar to the ones mentioned above (low, high, exact, and probabilistic assumptions are shown). To determine the assessment of the complexity of the selection of schemes, the flow of incoming wagons is determined, and it is assumed that the resulting $S$ schemes are formed. Therefore, the sorting of such necessary schemes is a complex problem, which has been discussed in detail in the various variants.

For example, let's sort the given numbers $S$ in ascending (descending) order. It is also noted that there may be the same numbers between them. The lowest probability evaluation solution is $S$-1. The lower limit for estimating the complexity of sorting $S$ numbers in ascending (descending) order is $\log _{2}(S !)$. According to [13], the complexity of any algorithm for sorting $S$ values is not less than $\log _{2}(S !)$.

Now we turn to the upper limits to sort the numbers $C$ in ascending (descending) order. The simplest sorting algorithms are the average quadratic sorting. However, there are more effective algorithms in science. In this case, a class of algorithms that assume the presence of structures in the sorted elements is considered. Structural elements are the values of the objective function described above for a set of two finite numbers. According to [14], we choose an algorithm of complexity $C \cdot n \cdot \log (n)$.

Let the ordering problem be structured as follows: A linear order belonging to set $X$ and belonging to this $\operatorname{seta}_{1}, \mathrm{a}_{2}, \ldots, \mathrm{a}_{n n}$ given the sequence of elements. To fulfill the following condition: $j \leq k$ in $a_{i j} \leq a_{i k}$ it is necessary to find the rule of the location of the elements $a_{i 1}$, $a_{i 2}, \ldots a_{i n}$, Algorithms for solving this problem are known.

Let us consider a set of numbers $S$. To compare $C(S-1) \log (S-1)$; it is possible to sort from a set of numbers $(S-1)$. First, we place the numbers $S-1$ on the $C(S-$ 1) $\log (S-1)$ comparison. We take the last numbers and divide the first numbers of $S-1$ into two sets (probably they are not equal to each other), comparing the last number with the $S-1$ numbers in the middle. As a result, two different situations can occur: $S-1$ pair or $S-1$ odd. In the first case $S-1=2 \cdot k+2$ in the second $S-1=(-2) \cdot k+2$.

Now we divide the rest of the last number into two again, and so on. This process continues until the last number finds its place. We can continue this situation until we 
compare $\left[\log _{2} n\right]+1$ (proof is the induction obtained by $S$ ) $[15,16]$. Thus, the result obtained on this process is as follows:

$$
C \cdot(\mathrm{n}-1) \cdot \log _{2}(n-1)+\left[\log _{2} n\right]+1 \leq C \cdot n \cdot \log _{2} n
$$

\section{Results and Discussion}

Selecting the weight (importance) of the assessment criteria is a complex informal process. Different methods can be used to determine the weight of each assessment criteria, but the most common of these is the expert assessment method. If the values of the target function are equal, both the vectors $\alpha_{j}$ and $\alpha_{k}$ can be considered optimal. Such an equation has no special meaning when determining the next direction of calculations according to the proposed algorithm and considers the description of this algorithm. Selection can be made by adding any additional assessment criteria to the compared options.

A criteria graph (tree) can be used to define a set of assessment criteria (Fig. 4). Graph peaks are criteria from $l$ to $n$. Each part of the graph defines specific criteria and standardizes the weight values for each branch $[17,18]$.

For example, we get incoming of wagon-flows of size $X$ and $Y$. This flow can be processed according to options $A, B, C, D$. We calculate the values of the several assessment criteria for each option. The directions for changing the assessment criteria are as follows:

$$
\alpha_{1,3,6,7} \rightarrow \min , \alpha_{2,4,5} \rightarrow \max
$$

The weight of the assessment criteria is distributed in ascending order of the number $\lambda_{i}$ according to the timing observations. The results of the target function calculation for these options are in the form of the following expression:

$$
f(A)>f(B)>f(C)>f(D)
$$

Therefore, option $A$ can be considered optimal for the given conditions; option $B$ has a first-class advantage over options $C$ and $D$. 


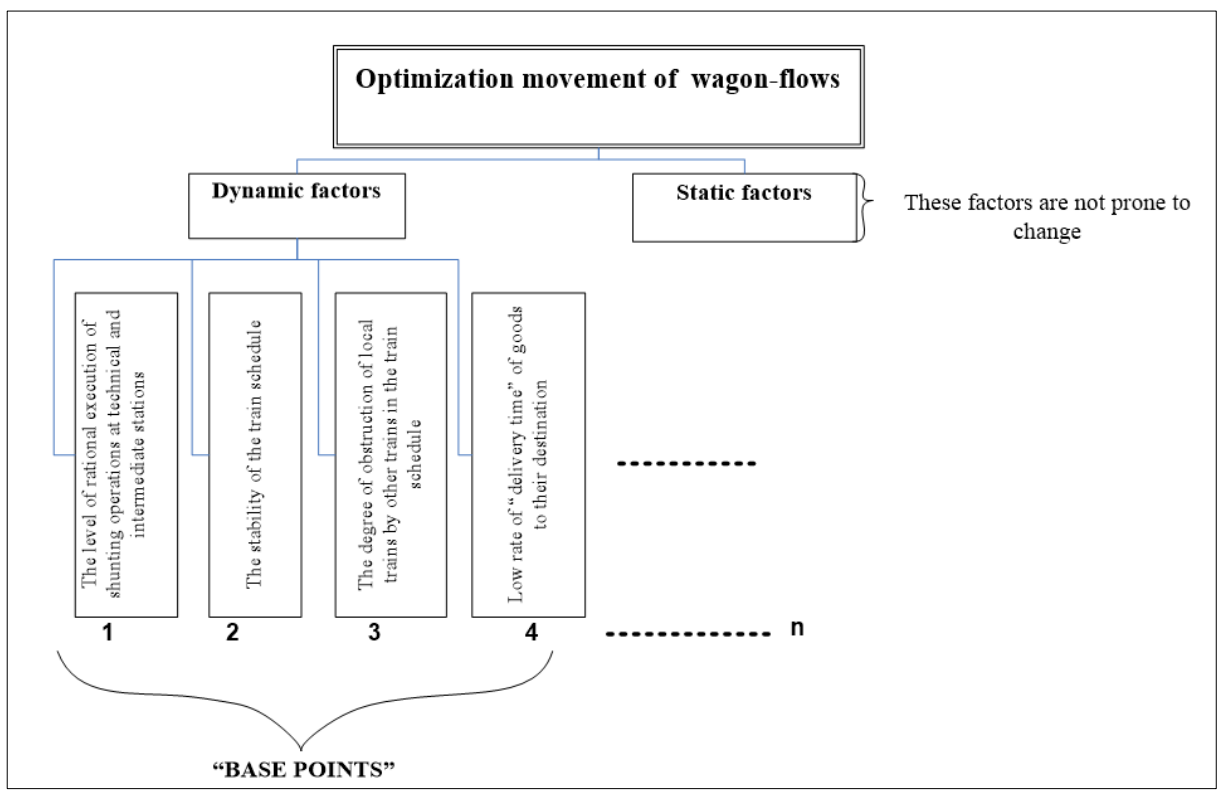

Fig. 4. Scheme for determining the set of assessment criteria for optimizing the movement of wagons.

Similar rows are constructed for all parameters studied. As a result of such design and comparison, it is possible to determine the factors affecting the wagon-flows and the optimal operation schemes of the facilities serving them. Implementation of this economic and mathematical method allows you to use the available opportunities to select the optimal solution to accelerate the local wagon-flows or improve performance and conduct technological measures to improve performance and select work sequences. However, insufficient capital investment in applying optimal options in the manufacturing sector and similar reasons may be an obstacle. In this case, additional restrictions will need to be added to this assessment criteria.

To optimize the local wagon-flows, experiments were conducted on the "Southern" site of JSC "Uzbekistan Railways". According to him, several parameters affecting the wagonflows were identified, the most significant parameters were selected based on assessment criteria $[19,20]$. The selected assessment criteria were placed as follows relative to their weight:

- the level of rational execution of shunting operations at technical and intermediate stations (equal to $39 \%$ of the variability of the overall parameters);

- stability of the train construction plan $(31 \%$ relative to the variability of the general parameters);

- the degree of obstruction of the movement of local trains by other trains in the train schedule (equal to $17 \%$ of the variability of the overall parameters);

- low rate of "delivery time" of goods to their destination (11\% relative to the variability of the overall parameters).

\section{Conclusion}

In conclusion, the parameters listed for accelerating the wagon-flows can take different values, the combination of which is a variable that affects the quality and quantity of their work. In this case, the optimized parameters ("base points") include the level of rational execution of shunting operations at technical and intermediate stations, the stability of the 
train schedule, the degree of obstruction of local trains by other trains in the train schedule, the rate of "delivery time". The existing and appropriate algorithmic processes allow for a quick and efficient selection of a solution to this problem. At this point, the ideal point method is the most common method in solving optimization problems. However, the simplification method is also a universal method, and optimal results can be achieved by using it. According to these methods, the set of performance criteria of the factors influencing the wagon-flows can be changed or supplemented with new assessment criteria.

\section{References}

1. J. Zhang, H. Yang, Y. Wei, P. Shang, The empty wagons adjustment algorithm of Chinese heavy-haul railway. Chaos, Solitons and Fractals, №89, pp. 91-99, (2016)

2. C. Shana, P. Russell, Z. Jian, Restructuring the Chinese Freight Railway: Two Scenarios, MPRA Paper No.88407, p. 32, (2018),

3. N. Lingaya, J. Cordeau, G. Desaulniers, J. Desrosiers, F. Soumis, Operational car assignment at VIA Rail Canada, Transportation Research Part B: Methodological, 36, №9, pp. 755-778, (2002), doi:10.1016/S0191-2615(01)00027-3.

4. H.J. Ko, A DSS approach with Fuzzy AHP to facilitate international multimodal transportation network, KMI International Journal of Maritime Affairs and Fisheries, pp. 51-70, (2009),

5. Sh.M. Suyunbaev, Zakonomernosti poezdoobrazovaniya na texnicheskix stantsiyax pri otpravlenii poezdov po nitkam tverdogo grafika, PhD Thesis, Saint Petersburg, PGUPS, p. 176, (2011)

6. Li Hong-Chang, Rong Chao-He, Song De-Xi, Applicability and Methods of Lean Production in Railway Transportation Organization: A Case Study of Urumqi Railway Bureau in China, International Journal of Railway, 1, № 2, pp. 45-58, (2008)

7. S.E. Bekzhanova, B.M. Issina, A.Z. Zhaksybaeva, S.S. Suyunbayev, Introduction of a single intellectual management system and automation of production processes on railway transport, Jour of adv research in dynamical \& control systems, 12, (6 Special Issue) pp. 706-712, (2020), doi: 10.5373/JARDCS/V12SP6/SP20201084.

8. Levin. D.Yu., Organization of car flows in market conditions, World of transport and transportation, 15, №4, pp. 178-192, (2017)

9. A.F. Borodin, Kompleksnaya sistema organizatsii ekspluatatsionnoy raboti jeleznodorojnix napravleniy, Doctoral Thesis, Moscow, Railway Research Institute of JSC Russian Railways, p. 491, (2000)

10. Wang, B.-H, He, S.-W, Song, Ruiqi, Wang, B., Stochastic dependent-chance programming model and hybrid genetic algorithm for car flow routing plan, Journal China Railway Society, №29 pp. 6-11, (2007)

11. J. Nong, L. Ji, Y.L. Ye, Z.J. Liu, Distributed algorithm for the optimization of railway car flow routing, China Railway Scientific, №29, pp. 115-121, (2008)

12. A. Papakhov. Using method of multitude of functions ratsyonalnoy organization vahonopotokov, Transportnыe sistemы i texnologii perevozok, №12, pp. 69-74, (2016)

13. A. Shen, Programmirovanie: teoremi $i$ zadachi. Nauchno-populyarnoe izdanie, in Lecture Notes in Programs, Moscow, p. 320, (2017).

15. T.I. Kashirtseva, Vibor ratsionalnogo sootnosheniya obemov rabot i texnicheskoy osnashennosti PTS, PhD Thesis, Moscow, MITE, p. 245, (2002)

16. P. Ernest, Mathematical Induction: A Pedagogical Discussion, Educational studies and Mathematics, pp. 173-189, (1984)

17. F. Novikov, Diskretnaya matematika dlya programmistov: Uchebnik dlya vuzov, in Lecture Notes in Programs, Saint Petersburg, p. 384, (2009). 
18. A.L. Kazakov, M.B .Petrov, A.M. Maslov, Multi-objective optimization of the region's transport system on the basis of its hypergraph, Ekonomika regiona, №4, pp. 199-208, (2014), doi:10.17059/2014-4-16.

19. N.M. Aripov, Sh.Sh. Kamaletdinov, Quality assessment of station commercial books and records at the railways of the Republic of Uzbekistan, Transport: nauka, texnika, upravlenie, №8, pp.64-67, (2019)

20. Sh.M. Suyunbaev, Sh.B. Jumaev, M.D. Axmedova, Process on sorting and selection of the many group trains on railways JSC "O'zbekiston temir yo'llari", Transport shyolkovogo puti, №3, pp. 30-38, (2020)

21. D. B. Baxodirovich, S. K. Kobiljonovich, S. S. Mansuraliyevich, Modeling of unproductive losses in the operation of a sorting station, Solid State Technology, 63 №6, pp. 6-19, (2020) 